\title{
Digital Divides?
}

\section{UK Film Council Strategy and the Digital Screen Network}

The UKFC Digital Screen Network strategy is designed to diversify the range of films available at cinemas around the UK, with special emphasis on provision of greater geographical equality in diverse programming offers. It will do this via the wider distribution of films that will become possible via digital technology. At heart, the scheme is audience focused and clearly aimed at growing and developing audience appetite for viewing a wider range of films. It is designed to be effective over the medium to long term. The strategy will encompass all types of cinemas, from existing specialized cinemas (art houses), independently owned cinemas, smaller circuit cinemas and multiplexes.

The Digital Screen Network, part 2 of paper presented to UKFC Board, January 2005.

\section{Introduction}

In retrospect it is easy to identify digital technology and the disruptive nature of the internet as two key factors shaping the broader screen landscape over the last decade or so. Debates around for example, piracy, the role of intellectual property (IP) and the impact of digital technology on the screen industries have recognized the importance of understanding the shift to digital (Balio, 2013, Iordanova and Cunningham, 2012; Ulin, 2014). Against this backdrop, this article examines the role that digitization and its wider ramification across the UK film industry's patterns of production, distribution and exhibition played in both the strategic thinking and operational practice of the UK Film Council (UKFC) during its lifetime (2000 - 2011). This support body for the Film Industry was set up under a New Labour government, and was abolished by the Conservative led Coalition government that came to power in 2010 .

The politics regarding the creation and demise of this key instrument of UK government policy with regard to film in the UK has been detailed elsewhere (Schlesinger, in press). While the key shifts in its strategic thinking and direction and the challenge of building a sustainable film sector are addressed in Doyle (2014). Drawing on original empirical research carried out as part of an AHRC funded study (1) what we are interested in here is mapping out the extent to which strategic thinking specifically around the impact of digital technology informed the direction and role that the UKFC took in engaging with what, in retrospect were industry changing processes. Was the UKFC too slow to identify the transformative impact that digital would have on all areas of the film industry? To what extent where its interventions around production and distribution and exhibition successful in achieving what they initially set out to deliver? Did the UKFC enable the film industry in the UK to fully address both the challenges and opportunities that the transformation to a digital environment posed over the period of its lifetime? At the core of this research is recognition of the ways in which digital impacted on film production, distribution and exhibition during the 2000s and the difficulties this posed to the UKFC as it attempted to satisfy the often competing agendas of these different constituent parts of the film sector in the UK. 
The first part of the article examines the important initial framing of the UKFC's strategic engagement with digital from 2000-2003. It then examines and evaluates one of the key interventions from the Council that directly addressed digital change, the development and implementation of the Digital Screen Network (DSN), before finally returning to account for the strategic shifts in the organization's thinking around digital that would take place over its lifetime.

\section{Early Thinking: $2000-2003$}

In his overview of the process of how public policy gets implemented within organizations, Peters (2014) identifies the growing complexity of the implementation process. He argues that the network style of implementation will often result with policies being 'made at the same time as they are being implemented' (Peters, 2014: 135). This suggests the supposedly top down driver of policy implementation is often less linear than it may appear and that this network process is often identified in studies of institutions. In this study around the UKFC there are a number of factors that shaped the backdrop against which we need to place its early thinking around the impact of digital technology and the internet. It is worth noting that by the late 1990s and early 2000s it was still unclear how digitization was going to play across the media industries more generally. There was a considerable degree of strategic uncertainty about how, or even in some quarters, if, the internet and digitalization would be the 'game-changers' which they subsequently turned out to be. Commercial newspapers, for example were busy setting up websites and giving away their journalism for free at this time, a model that in retrospect proved to be damaging to the industry (Brock, 2013).

Across the UK television industry commercial free-to-air (FTA) broadcasters were slow to recognize the impact of digitalization during the 1990s. The BBC, in contrast, would lead on digital strategic thinking during the 1990s, with its DG John Birt, widely credited with driving through strategic shifts in the ways in which the BBC thought about digital. He recalls:

The BBC ended up better positioned for the new century, for the new digital era, than any other established broadcaster in the world. But this was not a smooth and easy experience: it was a voyage into the unknown, propelled by curiosity, instinct, enterprise and luck. It was a journey marked by disasters narrowly averted, by intrigue, and by bad decisions as well as good ones (Birt, 2002: 452).

Thus even the often lauded digitally orientated BBC sees its DG John Birt acknowledge the uncertainty that characterized the transition to digital across the creative industries and the process of trial an error that was part of that process. It was against this backdrop that the UKFC came into being in 2000.

Paul Webster worked across the film production sector, including as Head of Production at Miramax Films in the mid 1990s, before then leaving to create Film Four at Channel 4. He was on the UKFC Board (2000-2004) and notes that: 'The thinking about digital at the start of the decade was I think very basically that this was the future, but nobody [across the industry] quite knew what the future would look like - I am not sure they do now' (Interview, 31, March, 2013). 
As Doyle (in press) has noted the task of creating a 'sustainable' film industry (without this ever being clearly articulated in terms of achievable goals) was one that to some extent both dominated and distorted the strategic focus of the UKFC in its initial three year planning cycle (2000-2003). Within this context, digital, beyond some concerns around issues of DVD piracy, was not at the forefront of the Council's thinking during the period. It is notable that in Chairman Alan Parker's famous 2002 speech on the state of the UK film industry and the role he saw the Film Council should play in shaping its future direction, digital technology and the internet barely merit a mention (Parker, 2002). Within the film making production community there was a growing discussion about the impact of digital technology, through digital video (DV) on the ability make low budget films, but little evidence that there was any consensus, that within a decade digital film would become the industry mainstream (James, 2001).

Neil Watson, Strategy Advisor to the UKFC acknowledges that in its start up mode the Film Council was not strategically focused on the impact that digital technology and the internet was having on the UK industry. He notes that:

when people were talking about sustainability [ ] the initial discussion [ ] were all framed in terms of quite an analogue vision of building film companies that worked across the value chain of cinema, trying to bring films into cinemas, into DVD and television, etc. No one was really talking about what impact the internet had at that point, because we were still grappling with it - and to the extent that we were talking about it no one was really talking about digital (Interview, 9 May, 2013)

Indeed within more traditional sections of the film production sector of the industry there was a degree of hostility to digital, and a view that $35 \mathrm{~mm}$ film making was not going to disappear quickly and would thus remain at the centre of mainstream commercial film making for some time. The production focus of the UKFC Board in its first iteration also helped to reinforce to some extent the perception that digital was some way off directly impacting on the industry in a significant manner during the early 2000s. Among parts of the exhibitor wing of the industry, often viewed as among the most conservative sectors of the industry, there was also resistance in addressing or even seriously contemplating the possible seismic changes and disruption that both digital technology and the internet might bring to that sector.

Thus a combination of an initial politically framed strategic agenda around building a sustainable film industry in the UK, with a particular in-built Board orientation towards focusing on the production sector, when allied with wider resistance among this area to acknowledge the impact of digital technology might have across the industry, resulted in less attention being focused on long term digital thinking. Fiona Clarke-Hackston (BSAC Chief Executive) suggests that criticism of the UKFC's failure to address digital with sufficient attention during this 2000-2003 period is however unfair, and needs to be placed within the context of the approaches to digital in other areas of the screen industries at that time. She argues:

I don't blame the UKFC, you play the political cards you have got, but I do think that this in some ways held them back, so I don't think they realized [re digital] what was going on, but I don't think they were alone in that either. Some of the broadcasters, such as ITV, were really slow to realize that. Sky got it years ago, and that is why Sky is worth more than ITV on the stock market [ ] a lot of people that didn't get it [digital] (Interview, 19 March, 2013) 
This is of course is not to suggest that debates or discussion around digital were absent within the UKFC. For example, the New Cinema Fund (NCF) under Paul Trijbits was explicitly set up to recognize digital and that the ways people were making films was changing. It could be argued that the UKFC saw the NCF, with its focus on low budget digital production, as the core focus of its digital intervention. Producer Paul Webster suggests that:

You know, one of Paul's early initiatives and kind of think tank idea was called 'Digital or Die', and the idea was that digital would revolutionise means of production, that budgets would come down, that people would be able to make films very simply and share them, much of which has come true. In the Film Council, as a whole I think, the attitude was very positive towards the idea of the digitalisation of the industry and therefore the democratisation of the business (Interview, 31 October, 2013).

From a strategic perspective, Neil Watson, while accepting that the UKFC were not as quick to focus on digital as they should have been, also argues that:

There were bits and pieces going on, but there wasn't a coherent focused approach to digital. I don't think we really talked to the technology companies and that kind of dialogue wasn't going on. [ ] you have actually got all these incumbent stakeholders who want you to stem the tide against digital at one point instead of embracing it. So that became a tension that you have to manage, and we got better at bracing the opportunities rather than just thinking about the challenges as we went on (Interview, 9 May 2013) .

With the strong producer representation on the Board during these early years of the Council, it would appear that little sustained thought was focused on the impact of digital on the distribution and exhibition aspects of the industry. To some extent this reflected much of the dominant thinking across the sector that viewed the UK industry as basically a cottage industry largely focused on production, this was of course one of the things that the UKFC wanted to alter. The arrival at the UKFC of Pete Buckingham as Head of Distribution and Exhibition in 2002 significantly altered this situation, although ironically digital strategy would only emerge almost as by-product of apparently more pressing strategic objectives for the UKFC around access to film.

\section{Into Tomorrow}

Pete Buckingham, appointed to the UKFC in 2002 as Head of the newly created post of Distribution and Exhibition, is widely viewed as the key architect of much of the UKFC's most important interventions in developing a strategic vision that placed digital at its core. Specifically the creation by Buckingham - working closely with Steve Perrin who had moved from Head of Research and Statistics - of the Digital Screen Network (DSN) across the UK which became a central aspect of the UKFC's intervention in the digital arena.

However, the digital transformation of the industry was not part of their brief. Steve Perrin recalls that: 'Our broad task was to develop strategies, using public funds, lottery money, to widen the range of films on offer to the cinema going public, basically we were tasked to do that. 
[ ] How we did it was up to us' (Interview, 6, November, 2013). Both Buckingham and Perrin had wide experience of the commercial distribution and exhibition aspects of the industry, and both were clear that if they were to build wider audiences for film and get a wider range of films being watched by audiences then UKFC attention needed to broaden from its dominant supply side intervention.

By 2003 the UKFC’s Digital Technology Strategy Group had produced an interim position paper (The Digital Strategy Group was the internal forum within the UKFC for debate on digital issues). This document (UKFC, 2003a) reflected the relative uncertainty across the film industry about the perceived impact that digitization would have across production, distribution and exhibition and noted that sections of the industry felt that 'claims about the predicted diffusion of technology are overstated.' This was far from the 'settled will' of the industry and the report also noted that many took 'the opposite view that current technological change represents a major paradigm shift' (UKFC, 2003a: 3). The document when discussing UKFC aims and objectives relating to digital strategy finally concluded with a rather anodyne strategic objective that was, 'To contribute to the exploration, development and adoption in Europe and beyond of new technologies especially in production, distribution and exhibition' (UKFC, 2003:4). It advocates both a 'watching brief' for the organization while suggesting it also acts as 'a catalyst for bold and imaginative strategic thinking' around digital strategy (UKFC, 2003: 6). It notes that three Digital Futures Seminars would take place over 2003/4 with the industry to help focus, enable and develop future scenario thinking about the role of digital across the industry.

In the end only two such seminars took place the first in June 2003 and the second in January 2004. They were important in that they crystallized some of the divergent thinking about the role and impact of digitization across differing sectors of the industry. The seminars saw senior UKFC managers meet with industry managers from across the film and screen sector including the BBC and Channel 4 to discuss digital's ability to reshape the sector. The term 'technology' was dropped from the second seminar which focused on the exhibition and distribution challenges faced by the industry, while the initial seminar had been more concerned with the way technology was changing skills and training needs, although this had also ranged widely across the impact of digital on the industry (UKFC 2003b: UKFC 2004). One area of difference that emerged in the second seminar was around the extent to which digital strategy merited becoming a dedicated and specific strategic priority of the UKFC. The record of the seminar notes that:

Neil Watson [UKFC] argued that digital should be viewed as a means to an end, as a facilitator; this meant that there shouldn't have to be a digital strategy for the FC; instead digital should be part of the means to a variety of FC ends rather an end in itself. Terry Ilott [Hammer Film] presented the opposite view that digital technology was far more than a means to an end, it was changing how everything in the film sector was done - he argued that the FC must do more than simply mainstream digital across its existing range of strategies (UKFC, 2004: 8).

In many ways this debate would continue both within the UKFC and the industry more generally and would remain unresolved until - as we discuss later in this article - 2007 when the UKFC would explicitly identify the transformative impact of digital on the industry in its policy (UKFC, 2007).

However by the time of the 2004 seminar, the Digital Screen Network (DSN) was already being talked about as a key digital initiative by the UKFC (although it would not be formally launched 
until later that year). In retrospect it would be this initiative that would prove to both to be the single largest investment by the UKFC in a digital programme and mark a move to engage with the distribution and exhibition sectors of the industry. Although as we noted above, what became a digital flagship initiative of the UKFC, emerged not from any specific shift in its thinking around digital strategy, but rather a more prosaic concern with its priority of extending access to film and engaging the widest possible audience for non specialist film.

\section{Becoming Digital: The Digital Screen Network}

For Peter Buckingham, the newly installed Head of Distribution and Exhibition, the challenge he faced was how best to utilise capital funds to realise the goal of extending the range of films available to the public. For Buckingham it was always about starting with the audience, rather than focusing on the production sector. He notes 'I am an audience person, I do try to build a policy from the ground up, that you work with the grain, you don't try to force something (on the audience)' (interview 3 July, 2008) (2). To achieve these goals Buckingham recalls that:

I had fifteen million pounds-worth of capital funds from the Arts Council [ ] which traditionally had been used for bricks and mortar for exhibition, basically, so that's what had been traditionally done, and in addition, there was a print and advertising fund, support fund for, which was then one million a year for 'specialised' films or 'art house' films and one million a year for 'British' films and there was a one million a year for three years of what they called an 'education' fund and that was it (Interview 3 July, 2008).

Working with Perrin, and drawing on market research they commissioned, both came up with digital cinema as the strategic way forward to enhance wider audience engagement with film. In 2003 digital cinema exhibition was being discussed in parts of the industry but nothing substantive had yet been developed. For example, the Digital Cinema Initiative (DCI) was a consortium of the major US studios that attempted to set an agreed standard for digital film allowing ease of screening of digital content. Although set up in 2002, it would be 2005 before they issued their DCI Specification version 1.0 which set out technological requirements for screening digital cinema. Being DCI compliant was viewed as important in the scheme. An early intervention into digital cinema in Sweden for example suffered as a result of equipment not being DCI compatible and being thus unable to show Hollywood films.

Significantly, neither Buckingham nor Perrin were experts in digital cinema, with both men, by their own admission industry strategists and not technologists. Perrin notes that having decided on digital cinema,

we set about learning about it, we went to manufacturers, we went to conferences, we spoke to technical experts to try and learn a bit about it. This was in the pre DCI days. There were good, solid, high definition projectors in those days, but they were $1.3 \mathrm{k}$, not the $2 \mathrm{k}$ or $4 \mathrm{k}$ you see today [ ] we spent a considerable time figuring out how could we harness the potential value of digital cinema to achieve our objectives, [ ] we came up with the concept of the digital screen project, which was, basically a way of spreading digital geographically, so that there was a representation of digital in most places around the country (Interview, 6 November, 2013). 
Strategically it is important to note then access rather than digital development, was a key driver initially in the development of the Digital Screen Network. As Steve Perrin argues:

A lot of people, I don't think deliberately but perhaps understandably misinterpreted our objectives. Our objective was not to promote the concept of digital. We saw digital cinema as a tool to achieve our aims and objectives. However, one of the spin offs, was that the UK got this taste of digital, began to think about it, and started to accommodate their thinking to it. So, that was one of the spin offs, but we did not set out to convert the world to digital. We said, here's a technology, we can use it as a means to an end (Interview, 6 November, 2013).

The original conception was simple, but in reality masked a myriad of complex logistical and technological challenges. At its core was the economic benefit that it was cheaper to make and distribute a digital film than a 35mm print film. As UKFC CEO John Woodward argues:

The digital screen work is not just for exhibition [ ] the economic value of the digital screen work is probably more important to the distribution sector, because it changes their business model for everybody when that happens, they had to stop making prints, they didn't need to spent $£ 700$ on a print, they could spend $£ 40$ on a digital file. So digitization has very serious implications for audiences and the diversity of films and the product that you could put in front of audiences, but in business terms, it's as important for the distribution sector, and was always intended that way (Interview, 30 April 2013).

Thus more copies of the film being made available offered the potential for wider dissemination of the content to cinemas. These required digital projectors in cinemas to screen the content and to agree that as part of the process of having substantial (but not all) costs covered by the scheme of projection installation they would show an increased amount of specialized film. When this was allied with changes in the Print and Advertising (P\& A) Fund that saw its budget increased and greater focus given to those specialized films it would choose to promote, it was hoped this would bring specialized films to a wider audience.

The tender to secure the delivery of the DSN through the installation of digital projectors was issued in March 2004, and the organisation tasked to deliver on the introduction of digital exhibition was Arts Alliance Media (AAM) lead by Thomas Hoegh. AAM had been involved in digital aspects of film distribution and exhibition through its Love Film arm and its own attempts to begin digitising cinemas. They won the tender against larger and more established companies in part according to Hoag because:

we provided a very simple and more or less foolproof system, whereas the nearest competitor who was the finalist with us, provided something which required a lot of extra costs and was complex to run (Interview, 31 March, 2013).

The scheme was launched on 9 August 2004, with a call to cinema owners wishing to secure the installation of digital screens. By the close of this process at the end of 2004, 280 eligible applications were received with a broad geographical spread (although with under representation in Northern Ireland, parts of Wales rural East Midlands, Cornwall and Scotland) and with 153 multiplex applications, 76 from specialised cinemas and 45 from commercial independent cinemas (UKFC, 2005). The scheme would lead to the installation of digital projectors in 212 
cinemas across the UK and create 240 digital screens. Of these $79 \%$ of the cinemas would be outside of London with almost $£ 12 \mathrm{~m}$ being spent on the project.

Two aspects of the scheme proved to be particularly controversial, one was the positioning of the projectors in the main screen, thus allowing easy access to screen Hollywood, as opposed to specialist film, and the other was the Virtual Print Fee (VPF) which it was felt added a disproportionate cost to distributors attempting to get small independent films screen time.

It is also clear that given that the DSN scheme was committed to engaging with the main commercial cinema exhibitors in the UK as well as the independent cinema chains that some form of commercial consideration was going to be part of the wider arrangement for these major exhibitors. The UKFC's CEO John Woodward accepts that by positioning the digital projectors in the main auditorium it benefited to some extent the Hollywood studios. He argues that:

I am not denying that the reality of where the projectors were sited [ ] if you look at the screening patterns, what you'll find is that overall the number of independent and niche films that were shown in cinemas during that period shot up, and that was as a result of digital projection. Does that mean that every film that the independent distributors and film makers wanted to get shown got shown, no of course it didn't, but compared to what was going on when they had 35mm projectors in those screens, the change was enormous (Interview, 30 April 2013)

Steve Perrin also acknowledges the criticism that the DSN attracted from parts of the industry as it gave money to the commercial sector. He argues that through the scheme:

We were agnostic as to the type of cinema, but we were very clear that we wanted geographical spread. One of the debates that took place was, [ ] why would someone like the Film Council want to give what was in those days, £60,000 worth of equipment to Odeon? They've got enough money of their own, whereas there were cinemas that could do with that sort of money [ ] if certain cinemas in certain locations had made certain contractual commitments to us, that fitted with our strategy and they were big, multiplex companies, then so be it. This was a commercially based strategy. This was not let's help the cinemas. [ ] we're not giving money to Odeon. We're saying to Odeon, you show a wider range of films for your local audience and what we would do was support the audience (Interview, 6 November, 2013).

He notes that a similar criticism came their way when the revamped P \& A fund selected particular films that it wished to promote. He recalls:

Some of those films came from big studio based companies. People say, why are you giving money to Warner Brothers? They can afford to do it themselves, but the answer being, yes, they can afford to do it themselves, but they aren't going to do it. If they're going to go out in the $35 \mathrm{~mm}$ cinema, with 30 copies, because that's what they think is right, there's no way in the world they're going to go out with 50, but if we go to them and say, look, this is what you've got. We think there's a market here, here and here, we'll support you if you go into those markets. Which they did, then we gave them 
money. So, no, they don't need our money, it's the local population for whom the film now becomes available that we're supporting, not Warner Brothers. [It was] a difficult concept to argue. (Interview, 6 November, 2013).

Between 2003 - 2009 specialised films released in the UK as a percentage of total releases increased by $18 \%$. Within this broad category, documentary film releases increased from 10 in 2000 to 56 in 2009, while foreign language releases also increased from 131 in 2002 to 161 by 2009, with year on year dips and spikes (UKFC, 2010b). Films such as Lust (2007) The Diving Bell and the Butterfly (2007) Che Part One (2008) and Broken Embraces (2008) all received UKFC support through the P\&A fund to bring these to wider audiences. For others within the industry there was a perception that extending the film audience could have been achieved via means other than the DSN such as targeting funds towards community based organisations committed to bringing cinema to new audiences. However, it was felt that the ability of Hollywood to benefit from the transformation was also achieved in more subtle ways. Heather Stewart the BFI's Creative Director of Programming suggests that:

the definition of specialist cinema I think was a bit too lax and so, you know, big American Indie pictures start to come into the category of specialist cinema and so in terms of the kind of tick boxing that those mainstream halls might have to do to prove that they were showing a wider range of films, it didn't really do much. It was just business as usual (Interview, 31 March 2013).

However perhaps the biggest issue that dampened some of the industry enthusiasm for the DSN was centred on the Virtual Print Fee (VPF).

\section{The Virtual Print Fee}

The VPF is a subsidy set by the film companies and paid by distributors to exhibitors to offset the costs of transforming cinemas into digital spaces. The savings on creating and distributing $35 \mathrm{~mm}$ prints that digital clearly allows, is to all intents and purposes not enjoyed by the distributors within the film industry chain. As a result there is an additional cost to independent films being distribution digitally that the technology has in reality made obsolete. A European Digital Cinema Forum (EDCF) held in London in April 2008 brought together many of the then 73 distributors in the digital cinema industry to discuss this issue. Of these only five operated with a market share above $10 \%$, so smaller distributors in reality had around $1 \%$ of the market. The VPF was widely viewed by this sector as an imposition on them, orchestrated by the major film companies. At the EDCF conference in 2008, Jim Slater (2008: 37) noted how Pete Buckingham acknowledged the issue:

[Buckingham] accepted that the VPF concept actually means that the industry is effectively duplicating the old analogue model of the cinema business for at least the next seven years, and although he saw that this meant that they couldn't make full use of the opportunities that digital can provide, he felt that most exhibitors would need funding via a VPF.

Thomas Hoegh CEO of AAM accepts that in hindsight this aspect of the business model related to the DSN project was and remains problematic. 
Yes, there's one thing that I would have done differently, and that would have been to try to negotiate with the studios exceptions to the VPFs, for the most marginal film, independent film. So some kind of scale would exist that if something went out on less than X prints, then that could be exempt from VPF. This is to make sure that there's growth in the film culture, that there was diversity in product, but it wouldn't have any meaningful economic impact in a detrimental sense from the studios perspective because we are talking about something here that would be less than a \% of box office annually anyway, that's the one thing I would like to have negotiated (interview, 31 March, 2013).

Hoegh suggests that while the VPF didn't block independent films getting distributed, that it did impact on the original goals of the scheme. He notes that:

I think films that needed to get out there got out there anyway, but I think we could have seen a lot more creative use of such an exemption to get really experimental stuff out. So the experimental stuff has not had access, it's easier to get a short film because they are exempt, so it's easier to get a short film out there than there is now to get a feature film at the very marginal end (Interview, 31 March, 2013).

For some observers such as Heather Stewart, Creative Director at the BFI, the VPF became part of a number of issues related to the UKFC's focus on the DSN as a means of delivering on its widening access to film priority.

For Stewart, the rolling costs of digital technology renewal and upgrading was always going to be a challenge and the VPF simply mitigated against access to the range of independent films envisaged. She argues that:

The UKFC thinking was, "If people in Britain want to have more access to a wider range of films including UK films, then the way to kind of democratise the access is to make it easier to show films". What I'm saying to you is that [the DSN] wasn't the right strategic decision because actually what you've done is made it very difficult for small distributors to get the digital prints in cinemas because it actually can work out more expensive than buying a 35mm film. [ ] We've got 35mm projectors that are 60 years old that are fine. While digital projectors need upgrading after four years, where's your capital budget? Now this isn't the Film Council's fault, but strategically I never quite understood why that was the number one thing you'd want to do because it didn't achieve the goals. You wound up making it hard for distributors and not achieving the kind of depth of choice that you might think it was going to achieve (Interview, 31 March 2013)

The VPF remains an issue in the distribution sector and was identified as such in the Chris Smith's Film Policy Review published in 2012 which noted that:

the Panel recognises that the Virtual Print Fee (VPF) mechanism, which has enabled the industry to finance digitisation across a large part of the UK's cinema estate will, if unchecked, have a continuing and detrimental impact on independent distributors and 
smaller exhibition venues. It is already having a negative impact on their capacity to make available British and specialised films to audiences across the UK (DCMS, 2012: 31).

Phil Clapp, CEO of the Cinema Exhibitors'Association (CEA), writing in the trade journal Cinema Technology in 2014 also acknowledges that the VPF still inhibits some aspects of the sector:

This is particularly the case when it comes to flexibility of programming, where the influence of VPF payments on behaviour will continue to be felt for some time to come, resulting in less immediate freedom when it comes to booking and programming than many had hoped would be the case in the digital age (Clapp, 2014: 18).

Clearly the impact of digitisation across the distribution and exhibition sectors will continue to re-shape the business models and the nature of these sectors for some time to come. The transformation from the dominance of $35 \mathrm{~mm}$ film prints to digital across the UK industry in the space of just over 10 years is striking and the ramifications for this transformation are being continually worked through.

The DSN was not envisaged originally as showcase for the UKFC's strategic thinking on digital and while the audience led drive to expand choice has happened it has also been uneven. For some industry figures such as Chris Chandler (UKFC Head of UK Partnerships) the things the Digital Screen Network was originally supposed to do such as extend the range of film available, it achieved mixed results, it did however in his opinion play a key role in shifting the exhibitor sector to digital (interview, 19 February, 2013). In his analysis of the UK film industry between 2001 and 2010, Sean Perkins (2012: 322) notes these years saw a rise in the specialized films released as a percentage of overall releases from 53\% in 2003 to $69 \%$ in 2009. In addition market share for these films also grew from 5\% to $15 \%$ and then dipped in 2010 to $6.3 \%$. He argues

While the overall market share for all specialized film categories remains low, interventions such as the National Lottery Prints and Advertising Fund have increased the release width of many specialized titles, enabling these titles to reach audiences outside London and the major cities (Perkins, 2012: 323).

The more specific use of the P \& A Fund to back European films such as The Lives of Others (2006) and Broken Embraces (2008) increased the number of prints available and helped establish the possibility of wider access for such films beyond the art house circuit.

So the DSN project had perhaps unintended consequences, being less successful in its original aims, but also facilitating a wider industry shift in structure and also strategic thinking about how digital was going to change all aspects of the film business. In this sense it echoes aspects of Hanson's (2007) suggestion that what we are seeing is technological consolidation, digital replacing celluloid, rather than major cultural and social shifts in film culture. For Phil Clapp, who worked in the early 2000s in the DCMS before becoming Chief Executive of the Cinema Exhibitors'Association (CEA), the lack of robust policing of the scheme, once digital projectors were in place, was with hindsight an aspect that shaped the inability of the DSN to deliver across all its original objectives. He argues: 
the Digital Screen Network was a pioneering initiative, there was nothing like it even in countries which were quite fond of public intervention, like France. And while it certainly wasn't the publicly-stated objective of the DSN, in terms of a beginning of an understanding of what the potential of digitalization might be, in terms of programming and other aspects, I think it gave us [the UK] a significant head-start. All pioneers suffer the same kind of fate and undoubtedly in hindsight the Film Council may have approached how it distributed the 238 projectors slightly differently. It probably should have, and I'll probably get shot by some of my members for saying this, been tougher with cinemas in terms of the objectives of the DSN around specialized film. [ ] the Film Council got tough too late.

Even if cinemas signed up to show a certain proportion of specialized film, the Film Council weren't really that serious about it. So people took the projectors, and said, well, actually, it's going to be too much hassle for them to remove the projectors, so I don't really need to worry about that. And it was only in the latter stages [2008/9], that the Film Council started to get tough [but by then] that ship had already sailed (Interview, 31 October, 2013).

However some critics of the UKFC recognize that whatever its original aims and objectives the DSN was important for the film industry in the UK. Philip Knatchbull, CEO of film content and distribution and exhibition company Curzon notes that whatever the original aims of the DSN project it was a UKFC success story:

I think that was really helpful actually, you see I think that demonstrates how, if you kick start something, it can really generate further progress in encouraging other people to look at it, so they kick started an amazing revolution, they probably, if they hadn't put the money in when they did, the UK probably wouldn't have been as early adopter of digital projection as it now is, practically every single major screen is being converted to digital, that isn't the case in Europe, I am convinced that actually that policy and strategy was a good one, there was a lot of criticism at the time when a lot of multiplex cinemas were accessing this public money, but again it's seed money you put a little bit in and they can see what they can do with it, and then they go actually, this really makes sense, we are going to invest a lot of money in transforming all our estate. My viewpoint is that worked and if they were to apply the same principle to production and distribution and exhibition as a joined up sort of approach, then I think you can reintroduce this idea of funding a number of different integrated companies (Interview, 18 June 2013)

As the DSN scheme came to its conclusion, digital was by the end of the decade moving into the mainstream positioning of UKFC thinking.

\section{Digital Moves Mainstream}

It is worth keeping in mind Street's (2012) argument that understanding the impact of technologies on innovative practices is always challenging not least as they often co-exist with previous forms. She notes how debates about digital in the UK are often linked with notions of 
innovation, however spurious they may eventually turn out to be. There is little doubt, that within film policy rhetoric by 2007 the UKFC had finally moved digital to the mainstream of its strategic thinking. Following industry consultation from November 2006 to February of the following year around the challenges faced by the film industry in the digital age the organization's three year plan acknowledged that:

There is a pressing need for all of the UK Film Council's funding priorities to be regularly reviewed in relation to the impact digital technology is having on film. There is no monopoly of wisdom on the practical consequences of the changes being driven by digital technology, but it is clear that public policy for film and the moving image must be supple and flexible if it is to maximise the opportunities which are likely to arise over the next few years (UKFC, 2007: 8).

Of course digital technology issues, initially around the production context, had been on the UKFC policy radar more or less since its inception, without ever having moved to the core of its strategic thinking. By 2004 (UKFC, 2004) for example, 'digital technology' was number 6 of seven areas identified as being in need of strategic development, yet with the exception of the DSN and the New Cinema Fund, while the rhetoric of digital was around, the specific policy focus on what exactly the role of the UKFC should be in this area was less clearly defined.

The 2007 three year plan marks a broader recognition of the transformative impact of digital on the screen industries, although the only new policy initiatives explicitly digital in focus included 'a Film Digitization and Marketing Fund (an enhanced Prints and Advertising Fund)' with a new budget of $£ 4 m$ and 'a UK-wide Digital Film Archives Fund of $£ 1$ million per year' (UKFC, 2007: 2). It was also noted that: future expansion of the Digital Screen Network, although itself widely acknowledged as innovative would be rejected on the grounds that there was 'limited support and strong views that the market will deliver [further expansion]' (UKFC, 2007: 15).

Yet when Tim Bevan became Chair of the UKFC in 2009 he felt that a major strategic rethink of the position of digital within the organization's thinking and practice was needed. He argued:

the whole Film Council needed to have a re-evaluation, if you like, a look at what its function was and how it sat within the media landscape at that point. I felt that the production side of it was in pretty good shape [ ] really what needed looking at was how the new world of distribution was going to sit and what effect that was going to have on the film industry basically, and that we needed to have our wits about it in terms of looking forwards. [ ] thinking of the profound effect that the internet might have on our industry [ ] whether the traditional models and the traditional windows of distribution could work, the coalition between television and theatrical distribution, video distribution, television distribution, all the rest of it - and just look at all of that very carefully indeed. So that was one of the things that we wanted to do. And then secondly, that we should set a proper sum of money aside for ... I think it was going to be called an "Innovation Fund”, where in terms of the new technologies and all the rest of it, where people were working in areas where they would have a substantial impact on our industry, be it in production, be it in distribution, be it in whatever basically - that people could make an application for funding to support that. Now that never actually came to fruition, that fund, because by the time we had just elected to proceed with it, is when we got shut down (interview, 29 April, 2014). 
The 2010 three year plan (UKFC, 2010) indicated that £5m was to be dedicated to the Innovation Fund in part looking at new business models for film in the digital age. Perhaps not surprisingly given the media landscape of 2010, this final unrealised three year plan gives a clear indication of the direction of strategic travel for the UKFC between 2010 - 2013 with a greater central focus on digital and its significant impact across the industry than is evident in any of its predecessors. Given the sudden demise of the UKFC it would of course remain a plan unrealised.

\section{Conclusion}

In his discussion of film policy Newsinger (2012: 141) notes how much writing about the UK film industry treats it as a 'single entity' and as a result fails to understand its differing sectors. This UK case study has been particularly interested in the distribution and exhibition elements of the industry and their interface with UKFC policy with regard to digital. As Peters (2014) has noted, how policy gets implemented in organizations is increasingly driven by the range of networks they are located within, and the UKFC was a highly networked organization, often trying to reconcile the competing demands of a complex industry. A more detailed engagement with that organization's interplay with the production sector through for example the New Cinema Fund is a story to be told elsewhere. What is argued here is that, almost initially by default, the DSN became the most high profile UKFC intervention in the digital arena during its lifetime. It is ironic that given this, its origins came out of a drive to extend access to specialized film, rather than help transform the distribution and exhibition industry for the digital age. As the DSN rolled out and evolved it also had significant unintended consequences. For Thomas Hoegh CEO of AMM it:

gave the independent sector a head start, and not just cinema, but also the distributors, it gave them a head start to figure this [digital] out, so I think they were in a much better position than anywhere else in the world to think about what the practical realities of the digital film future would look like. I think it enabled many cinema owners to think radically different about how they run their cinemas. The whole aspect of alternative content has become now a serious business and most importantly, a risk mitigator in the release calendar, so a programmer can now sit and say, oh there's weakness in October, let's see if we can find some alternative programmes we can put in there, so that we don't have a deep dip in the worst weeks, that's the biggest contribution for alternative content and it's becoming more of a core element [for cinemas] (Interview, 31 March, 2013).

Other professionals located across differing parts of the industry, such as producer Paul Webster echo the view that:

without doubt on the exhibition side of thing, the Digital Screen Network really helped oil the wheels. It would have happened anyway - it has happened all over the world, but they [the DSN] sped up the process. Now if they hadn't existed at all where would we be today? Probably, you know, probably more or less the same kind of landscape, but I think in getting here the journey was eased by the Film Council - I think it was a very, very potent enabler in that area and kind of successfully bridged the gap between public policy and private innovation (Interview, 31 October, 2013) 
Others are more critical of the general manner in which the UKFC never, in their view got to grips with the role and impact of digital across the sector. For example Chris Chandler (UKFC Head of UK Partnerships; Consultant to the BFI) argues that:

The Film Council happened to exist over the decade, the rough decade when digital film making became a real thing. [ ] I think that arguably more interest could have been shown in digital experiments rather than the use of digital to do things [Yet] their support for the shift to digital exhibition I think was very good (Interview, 19 February 2013).

In one sense the UKFC was unclear of how digital would impact and play out and in this they actually reflected the uncertainty that existed across differing sectors of the film industry in the UK in the first decade of the new century. The organisation initially saw digital and its role though a production lens, and not until after Pete Buckingham arrived in late 2002 and energised, with Steve Perrin the distribution and exhibition arms of the UKFC did it develop a digital core through the DSN, which although never intended to be so, became its leading digital legacy. What emerges from this research is the extent to which digital strategy at the UKFC progressively emerged over the years and then often played out with unintended consequences. It also demonstrates the real policy challenge of addressing and understanding change taking place across a connected but also highly disparate industry such as film.

By 2007, the tide was turning and at a rhetorical level at least digital was moving up the strategic agenda, although whether it should be embedded in all UKFC activity or become a dedicated priority was still unresolved in UKFC thinking. By 2009, the Chair of the UKFC Tim Bevan and his root and branch re-evaluation changed this and the focus from then until the organisation's demise was in helping the transformation of the industry to engage fully with mainstream digital environment; a task ultimately of course that it would not given time to deliver on.

\section{References}

1 This is an Arts and Humanities Research Council funded project (AH/JOO457X/1) entitled 'The UK Film Council: A Case Study of Film Policy in Transition which runs from October 2012 - September 2014. Principal Investigator: Gillian Doyle, CoInvestigators: Philip Schlesinger and Raymond Boyle: Research Associate: Lisa Kelly.

2 This interview was carried out by Philip Schlesinger, as part of another AHRC funded project in 2008 which carried consent for it to be used in future publications.

\section{Bibliography}

Birt, J. (2002) The Harder Path; London: Time Warner Books.

Balio, T. (2013) Hollywood in the New Millennium, London: BFI.

Brock. G. (2013) Out of Print: Newspapers, Journalism and the Business of News in the Digital Age; London: Kogan Page.

Clapp, P. (2014) 2014- the year of digital learning, Cinema Technology, March. 
DCMS (2012) UK Film Policy Review: A Future for British Film: It Begins With the Audience, London: DCMS

Doyle, G. (2014) Film Support and the challenge of 'sustainability': On wing design, wax and feathers and bolts from the blue, Journal of British Cinema and Television, 11 (2-3): $129-51$.

Hanson. P. (2007) ‘Celluloid or Silicon?’ Digital Cinema and the Future of Specialised Film Exhibition, Journal of British Cinema and Television, Vol 4. No 2. 370 -383.

Iordanova, D. and Cunningham, S. (eds.) Digital Disruption: Cinema moves On-Line, St Andrews: St Andrews Film School.

James, N. (2001) Digital Deluge, Sight and Sound, 20-24, October.

Newsinger, J. (2012) British Film Policy in an Age of Austerity, Journal of British Film and Television, Vol. 9 No. 1. $133-144$.

PACT (2010) A New Business Model for UK Film Producers, Olsberg/SPI: London.

Parker, A. (2002) Building a Sustainable UK Film Industry A presentation to the UK film industry. Sir Alan Parker CBE, Chairman, UK Film Council, November .

Perkins, S. (2012) Film in the UK, 2001 -10: A Statistical Overview, Journal of British Cinema and Television, Vol. 9. No. 3. 310-332.

Peters, B. G. (2014) Implementation structures as institutions, Public Policy and Administration, Vol. 29 (2) 131- 144.

Schlesinger, P. (in press) The Creation and Destruction of the UK Film Council, in Oakley, K. and O'Connor, J. (eds.) The Routledge Companion to Cultural Industries, Routledge: London.

Slater, J. (2008) EDCF WORKSHOP: the strategic implications of digital cinema for film distribution, Digital Projection, June.

Street, S. (2012) Digital Britain and the Spectre/Spectacle of new Technologies, Journal of 
British Film and Television, Vol. 9 No. 3; 377-399.

UKFC, (2003a) Digital Technology Strategy: An Interim Position Paper, April, UKFC: London.

UKFC, (2003b) Digital Technology Futures Seminar, 24 June, UKFC; London.

UKFC (2004a) Digital Futures Seminar, 29 January, 2004, UKFC: London.

UKFC (2004b) The Second Three Year Plan: Funding and policy priorities April 2004 - March 2007. UKFC: London.

UKFC (2005) The Digital Screen Network, paper presented to UKFC Board, Janaury.

UKFC (2007) Film in the Digital Age:, UK Film Council policy and funding priorities April 2007 - March 2010. UKFC: London

UKFC (2009a) Delivering Digital Inclusion: An Action Plan for Consultation, A Response from the UK Film Council, UKFC: London.

UKFC (2009b) Response to Digital Britain: The Interim Report, 12 March, 2009. UKFC: London.

UKFC (2009c) UKFC Response to Copyright in a Digital World - What Role for a Digital Rights Agency, UKFC: London.

UKFC (2010a) UK Film: Digital Innovation and Creative Excellence, UKFC: London UKFC (2010b) The Statistical Year Book 2010: UKFC: London.

Ulin, J.C. (2014) The Business of Media Distribution: Monitizing Film, TV and Video Content in an On-line World, New York and London: Focal Press, $2^{\text {nd }}$ edition. 